\title{
Factors Associated with School Absence Among Children with Symptomatic Asthma, United States, 2002-2003
}

\author{
Lara J. Akinbami, M.D., ${ }^{1,2}$ Jennifer D. Parker, Ph.D., ${ }^{1}$ and Sarah Merkle, M.P.H. ${ }^{3}$
}

Children with asthma miss nearly 13 million school days annually due to asthma. We sought to examine risk factors for asthma-related school absence among children with symptomatic asthma to discern risks uniquely associated with symptomatic asthma. We analyzed 2002-2003 National Health Interview Survey data for children ages $5-17$ years with symptomatic asthma $(N=905)$, that is, those with a reported asthma diagnosis and $\geq 1$ asthma attack(s) in the previous year. Among the population of children with symptomatic asthma, we used logistic regression to assess the association between risk factors and asthma-related school absences. We also examined nonasthma absences among this population to assess if risk factors for asthma-related absences differed from those for other absences. Finally, we examined absences among children without asthma for comparison. A greater proportion of children with symptomatic asthma missed school compared with children without asthma. Overall, 59\% of children with symptomatic asthma had $\geq 1$ asthma-related absence in the past year. Among this group, presence of an adult household smoker was associated with an increased adjusted risk ratio for asthma-related school absence [adjusted risk ratio $=1.25(1.10,1.42)]$ as were race/ethnicity other than non-Hispanic white, low parental education, and reported health status less than "very good/excellent." Greater asthma healthcare resource use (emergency department visits and preventive medication use) were also associated with higher risk. For nonasthma-related absences among children with symptomatic asthma, only having no usual source of healthcare emerged as a risk factor. Exposure to an adult household smoker and greater asthma healthcare use were associated with $\geq 1$ asthma-related school absence among children with symptomatic asthma. Asthma-related school absences may help identify children in greater need of asthma evaluation and management.

\section{Introduction}

$\mathrm{I}$ N 2003, CHILDREN WITH ASTHMA missed 12.8 million Ischool days due to asthma based on parent report. ${ }^{1}$ Asthma-related school absenteeism raises concern due to the costs of potential impact on school performance and parental work absences. Research has focused on whether children with asthma miss more school and thereby suffer academic consequences. $^{2-5}$ Studies that assessed number of absences using school district data found more absences among children with asthma compared with those without, ${ }^{2,3}$ whereas another study of a school-based asthma management program calculated percent attendance and found no difference between students with asthma and overall. ${ }^{4}$ A study based on a 1988 nationally representative survey with parent-reported missed school days concluded that children with asthma miss more school and have a greater risk for learning disability, but not for grade failure or suspension/expulsion compared with children without any health conditions. ${ }^{6}$ More recently in studies based on school district data, no differences in standardized test scores ${ }^{5}$ or school performance ${ }^{3}$ were found between children with and without asthma.

There has been less focus on identifying risk factors for school absences. Effective management tools exist to prevent asthma morbidity, ${ }^{7}$ yet many children remain with symptoms and poor control. Nighttime awakenings in particular have been associated with school absences, educational impacts, and parental work absenteeism. ${ }^{8}$

Our objective was to assess risk factors for asthma-related school absence among a nationally representative sample of children with symptomatic asthma from the National Health Interview Survey (NHIS). To assess if these risk factors for asthma absences differ from those for other illness, we also analyzed nonasthma absences among these children with

\footnotetext{
${ }^{1}$ National Center for Health Statistics, Centers for Disease Control and Prevention, Hyattsville, Maryland.

${ }^{2}$ U.S. Public Health Service, Rockville, Maryland.

${ }^{3}$ National Center for Environmental Health, Centers for Disease Control and Prevention, Atlanta, Georgia.
} 
symptomatic asthma. For comparison, in a secondary analysis, we further assessed risk factors for general illness/ injury absences among children without asthma.

\section{Methods}

\section{Data source}

The NHIS includes a representative sample of the U.S. noninstitutionalized civilian population. Detailed health information is collected in a household interview for a randomly selected sample adult and, if children are present, a sample child. For children $<18$ years of age, a knowledgeable adult (usually a parent) provides a proxy report of health conditions. The 2002 and 2003 NHIS each contained asthma modules with supplemental questions about asthma. ${ }^{9} \mathrm{We}$ analyzed data for children aged 5-17 years with symptomatic asthma, that is, with an asthma diagnosis ("Has a doctor or other health professional ever told you that your child has asthma?") and recent symptoms ("During the past 12 months, has your child had an episode of asthma or an asthma attack?") with no missing covariates $(n=905)$ (Fig. $1)$. Because we were interested in risk factors that may be unique for asthma-related school absence among children with symptomatic asthma, we further assessed nonasthma absences among children with symptomatic asthma. As a

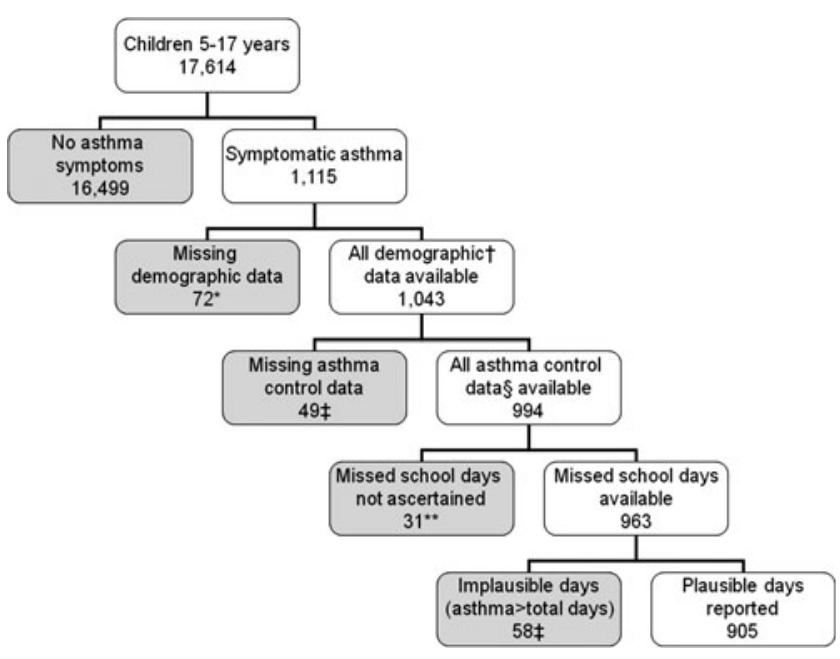

FIG. 1. Exclusions. *Missing parental education: compared with included study population, more likely to be nonHispanic black, live in a single parent family and to have family income below poverty level, public/no health insurance, an asthma ED visit in the past year, and asthma-related school absence. ${ }^{\dagger}$ Includes age, gender, race/ethnicity, allergy status, reported health status, usual source of health care, health insurance, smoke exposure, family structure, number of children in the household, parental education, family income, urbanicity and region of residence, and interview quarter. No significant differences from included study population. SIncludes preventive medication use, asthma ED visit, and received an asthma management plan. ${ }^{* *}$ As a group, children with missed or implausible school days, compared with included study population, were more likely to be non-Hispanic black or Puerto Rican, to have parents with low education, family income below poverty level, public/no health insurance, to have an asthma ED visit in the past year, and less likely to be reported in very good/excellent health or have an asthma management plan. comparison, we also assessed general illness/injury absences among a separate population of children without an asthma diagnosis $(n=13,830)$. The NHIS did not ascertain asthmaspecific school absences for children with a diagnosis of asthma but no episode/attack in the past year. Therefore, they were excluded $(n=2,669)$.

\section{Asthma, total, and residual absence days}

Two questions ascertained school absences. Only the sample of children with symptomatic asthma received the first question, which measured asthma absence days: "During the past 12 months, how many days of (daycare or preschool/school/school or work) did your child miss because of (his/her) asthma?" All sample children received the second question, which measured total absence days: "During the past 12 months, about how many days did your child miss school because of illness or injury?" These questions occurred in different survey sections. Although respondents for children with symptomatic asthma were not explicitly instructed to include asthma absence days in total absence days, we anticipated that they would do so. Children with symptomatic asthma who had more asthma absences than total absences were excluded $(n=58)$. Among children with symptomatic asthma, we also calculated residual absence days by subtracting asthma absence days from total absence days to assess whether risk factors differed for other illness / injury absences.

\section{Covariates and risk factors}

Age was categorized as 5-9 years, 10-13 years, and 14-17 years to capture the nonlinear relationship between school absence and age. Race/ethnicity was categorized in $5 \mathrm{mu}-$ tually exclusive categories.

Allergy status was categorized dichotomously as any reported allergy (hay fever, other respiratory allergy, eczema, and/or food allergy) versus none.

Asthma severity and control measures outlined in the National Asthma Education and Prevention Program clinical guidelines ${ }^{7}$ were not available. Rather, the NHIS provides downstream indicators, which we characterized as "asthma healthcare and resource use": (1) ever using preventive asthma medication [assessed with the question "Has your child EVER taken the preventive kind of ASTHMA medicine used everyday to protect (his/her) lungs and keep (him/her) from having attacks? Include both oral medicine and inhalers. This is different from inhalers used for quick relief"] and (2) an asthma emergency department (ED) visit in the past 12 months. We included a third covariate-receiving an asthma management plan-although not as a severity indicator given that all children with asthma should receive a plan. ${ }^{7}$ Disentangling asthma severity and control is difficult given that management and interventions impact disease manifestations. Further, healthcare access, use, and quality affect observed asthma symptoms and vary by socioeconomic status and race/ethnicity. ${ }^{10-13}$ Although not ideal, the indicators at hand (ED visit and preventive medication use) can help identify children more likely to face a significant impact from asthma.

Health status was included as a measure of perceived child vulnerability that could impact caretakers' decisions to send a child to school, and was categorized as "fair/poor," "good," and "very good/excellent." 
Table 1. Sample Characteristics, Percent $^{a}$ (STANDARD ERror), 2002-2003

\begin{tabular}{|c|c|c|c|}
\hline & $\begin{array}{c}\text { Children } \\
\text { w/symptomatic } \\
\text { asthma } \\
(n=905)\end{array}$ & $\begin{array}{c}\text { Children w/out } \\
\text { asthma } \\
\text { diagnosis } \\
(n=13,830)\end{array}$ & $\begin{array}{c}P \\
\text { value }^{\mathrm{b}}\end{array}$ \\
\hline \multicolumn{4}{|l|}{ Age group } \\
\hline $5-9$ years & $37.1(1.9)$ & $37.6(0.5)$ & \multirow[t]{3}{*}{0.04} \\
\hline 10-13 years & $36.7(1.9)$ & $32.4(0.5)$ & \\
\hline 14-17 years & $26.2(1.7)$ & $30.0(0.5)$ & \\
\hline \multicolumn{4}{|l|}{ Gender } \\
\hline Male & $59.8(2.0)$ & $49.8(0.5)$ & \multirow[t]{2}{*}{$<0.001$} \\
\hline Female & $40.2(2.0)$ & $50.2(0.5)$ & \\
\hline \multicolumn{4}{|l|}{ Race/ethnicity } \\
\hline $\mathrm{NH}$ white & $61.9(1.9)$ & $63.6(0.7)$ & \multirow[t]{5}{*}{$<0.001$} \\
\hline NH black & $17.0(1.5)$ & $13.1(0.5)$ & \\
\hline AIAN/other & $11.9(1.3)$ & $9.9(0.3)$ & \\
\hline Puerto Rican & $3.0(0.6)$ & $1.3(0.1)$ & \\
\hline Mexican & $6.1(0.9)$ & $12.1(0.4)$ & \\
\hline \multicolumn{4}{|l|}{ Allergy status } \\
\hline Any allergy ${ }^{\mathrm{c}}$ & $66.1(1.8)$ & $22.9(0.4)$ & \multirow[t]{2}{*}{$<0.001$} \\
\hline No allergy & $33.9(1.8)$ & $77.1(0.4)$ & \\
\hline \multicolumn{4}{|l|}{ Asthma action plan } \\
\hline Given asthma plan & $47.8(2.0)$ & $-^{\mathrm{d}}$ & \multirow[t]{2}{*}{ - } \\
\hline No asthma plan & $52.2(2.0)$ & - & \\
\hline \multicolumn{4}{|l|}{ Preventive medicine } \\
\hline Medication use & $62.4(1.8)$ & - & \multirow[t]{2}{*}{ - } \\
\hline No medication use & $37.6(1.8)$ & - & \\
\hline \multicolumn{4}{|l|}{ Asthma ED visit } \\
\hline ED visit & $25.6(1.6)$ & - & \multirow[t]{2}{*}{ - } \\
\hline No ED visit & $74.4(1.6)$ & - & \\
\hline \multicolumn{4}{|l|}{ Reported health status } \\
\hline Fair/poor & $8.3(1.0)$ & $1.3(0.1)$ & \multirow[t]{3}{*}{$<0.001$} \\
\hline Good & $27.9(1.8)$ & $13.7(0.4)$ & \\
\hline Very good/excellent & $63.8(1.9)$ & $85.0(0.4)$ & \\
\hline \multicolumn{4}{|l|}{ Usual source of care } \\
\hline Clinic/OPD/other & $15.9(1.4)$ & $18.3(0.5)$ & 0.002 \\
\hline Private office/HMO & $79.9(1.5)$ & $75.2(0.6)$ & \\
\hline ED/no place & $4.1(0.7)$ & $6.5(0.3)$ & \\
\hline Health insuranc & & & \\
\hline Any private & $64.7(1.9)$ & $67.7(0.6)$ & $<0.001$ \\
\hline Public only & $28.8(1.8)$ & $22.1(0.5)$ & \\
\hline Uninsured & $6.5(1.0)$ & $10.2(0.3)$ & \\
\hline Smoke exposure & & & \\
\hline Household smoker & $23.1(1.6)$ & $19.8(0.4)$ & 0.04 \\
\hline Unknown & $76.9(1.6)$ & $80.2(0.4)$ & \\
\hline Family structure & & & \\
\hline Single parent & $22.5(1.6)$ & $16.9(0.4)$ & $<0.001$ \\
\hline Married parents & $43.1(1.9)$ & $49.3(0.6)$ & \\
\hline Other 2 adult & $34.4(1.8)$ & $33.8(0.5)$ & \\
\hline Household children & & & \\
\hline 1 child & $22.7(1.4)$ & $19.7(0.3)$ & NS \\
\hline 2 children & $40.8(1.9)$ & $40.5(0.3)$ & \\
\hline $3+$ children & $36.5(2.0)$ & $39.8(0.5)$ & \\
\hline Parental education & & & \\
\hline$<$ High school & $9.0(1.1)$ & $12.6(0.4)$ & 0.01 \\
\hline $\begin{array}{l}\text { High school } \\
\text { diploma }^{\mathrm{e}}\end{array}$ & $24.3(1.6)$ & $23.4(0.5)$ & \\
\hline College/vocational & $34.5(1.9)$ & $31.6(0.5)$ & \\
\hline Bachelors degree & $17.6(1.5)$ & $19.6(0.4)$ & \\
\hline Postgraduate degree & $14.7(1.5)$ & $12.8(0.4)$ & \\
\hline Family income & & & \\
\hline$<$ poverty & $18.2(1.6)$ & $15.8(0.5)$ & NS \\
\hline $100 \%-199 \%$ poverty & $18.9(1.8)$ & $21.0(0.5)$ & \\
\hline $200 \%-499 \%$ poverty & $44.4(2.0)$ & $43.3(0.6)$ & \\
\hline $500 \%+$ poverty & $18.6(1.6)$ & $20.0(0.5)$ & \\
\hline
\end{tabular}

(Continued)
TABLE 1.

(CONTINUED)

\begin{tabular}{lccc}
\hline & $\begin{array}{c}\text { Children } \\
\text { w/symptomatic } \\
\text { asthma } \\
(n=905)\end{array}$ & $\begin{array}{c}\text { Children w/out } \\
\text { asthma } \\
\text { diagnosis } \\
(n=13,830)\end{array}$ & $\begin{array}{c}P \\
\text { value }^{\mathrm{b}}\end{array}$ \\
\hline Urbanicity & & & \\
Central city & $26.0(1.8)$ & $26.0(0.7)$ & NS \\
Other MSA & $55.2(2.1)$ & $53.9(0.9)$ & \\
Outside MSA & $18.8(1.8)$ & $20.1(0.7)$ & \\
Region & & & \\
Northeast & $20.8(1.7)$ & $17.7(0.5)$ & NS \\
Midwest & $24.3(1.7)$ & $23.6(0.6)$ & \\
South & $34.3(2.0)$ & $36.7(0.7)$ & \\
$\quad$ West & $20.6(1.9)$ & $21.9(0.6)$ & \\
Interview quarter & & & \\
1st quarter & $24.9(1.7)$ & $25.2(0.7)$ & NS \\
2nd quarter & $24.9(1.8)$ & $24.8(0.7)$ & \\
3rd quarter & $22.6(1.7)$ & $25.1(0.7)$ & \\
4th quarter & $27.6(1.9)$ & $25.0(0.7)$ & \\
\hline
\end{tabular}

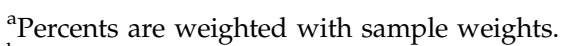

${ }^{b} P$ value based on chi-square test for differences in each categorical variable.

${ }^{\mathrm{C}}$ Children reported to have hay fever, other respiratory allergy, eczema, and/or food allergy.

${ }^{\mathrm{d}}$ The National Health Interview Survey did not assess children without asthma for asthma interventions or outcomes.

eIncludes Graduate Equivalency Diploma (GED) and equivalent diplomas.

NH, non-Hispanic; AIAN, American Indian/Alaska Native; ED, emergency department; OPD, hospital outpatient department; HMO, Health Maintenance Organization; MSA, metropolitan statistical area.

Indicators of health care access included having a usual source of health care (doctor's office/Health Maintenance Organization, clinic/hospital outpatient department/other place, or ED/no usual place) and health insurance status (private, public, or uninsured). Public health insurance included Indian Health Service, military insurance, State Children's Health Insurance, Medicaid, Medicare, or other public insurance.

Exposure to household smoking could be only indirectly measured, and was categorized as "yes" for children linked to sample adults who reported current smoking. Smoking status of other household members was not ascertained. Children either linked to a nonsmoking sample adult or not linked to any sample adult were categorized as having "unknown" exposure. To assess misclassification bias, we analyzed 8,974 child records in the 2005 NHIS in which the sample adult was also asked if anyone else smoked inside the home in a special supplemental questionnaire. This question allows estimation of the percentage of the 2002-2003 NHIS sample that would be misclassified as having unknown exposure when someone other than the sample adult smoked.

Household structure was categorized as single parent, married parents, and other 2-adult household. The number of children in the household $<18$ years of age was categorized as "one," "two," and "three or more" to examine bivariate associations, but was included as a continuous variable in logistic models.

We defined highest level of parental education using 5 categories. U.S. Census poverty thresholds based on gross money income and family size ${ }^{14}$ were used to categorize family poverty status. We used NCHS-provided imputed 
Table 2. Percent $^{a}$ (Standard Error) with $\geq 1$ Absence Days Among Children 5-17 Years With And Without Symptomatic Asthma, 2002-2003

\begin{tabular}{|c|c|c|c|c|}
\hline & \multicolumn{3}{|c|}{ Children with symptomatic asthma $(n=905)$} & \multirow{2}{*}{$\begin{array}{c}\text { Children w/out asthma }(n=13,830) \\
\geq 1 \text { total absence days }\end{array}$} \\
\hline & $\begin{array}{c}\geq 1 \text { total } \\
\text { absence days }\end{array}$ & $\begin{array}{l}\geq 1 \text { asthma } \\
\text { absence days }\end{array}$ & $\begin{array}{l}\geq 1 \text { residual } \\
a b s e n c e \text { days }\end{array}$ & \\
\hline Total & $88.9(1.2)$ & $58.6(1.8)$ & $57.9(1.9)$ & $71.4(0.5)$ \\
\hline \multicolumn{5}{|l|}{ Age group } \\
\hline 5-9 years & $88.5(2.2)$ & $63.0(3.1)$ & $46.5(3.3)$ & $72.0(0.9)$ \\
\hline 10-13 years & $90.1(2.0)$ & $58.4(3.1)$ & $61.1(3.2)$ & $72.2(0.9)$ \\
\hline $14-17$ years & $87.6(2.4)$ & $52.7(3.5)$ & $69.5(3.2)$ & $69.8(0.8)$ \\
\hline$P$ value $\mathrm{b}^{\mathrm{b}}$ & NS & NS & $<0.001$ & NS \\
\hline \multicolumn{5}{|l|}{ Gender } \\
\hline Male & $88.0(1.7)$ & $61.4(2.5)$ & $54.2(2.5)$ & $70.7(0.7)$ \\
\hline Female & $90.2(1.9)$ & $54.5(2.9)$ & $63.4(2.8)$ & $72.1(0.7)$ \\
\hline$P$ value & NS & NS & 0.016 & NS \\
\hline \multicolumn{5}{|l|}{ Race/ethnicity } \\
\hline NH white & 89.8 (1.6) & $52.2(2.4)$ & $67.9(2.3)$ & $77.5(0.6)$ \\
\hline NH black & $86.1(3.2)$ & $71.1(4.1)$ & $35.8(4.3)$ & $59.0(1.5)$ \\
\hline AIAN/other & $88.9(3.2)$ & $62.5(5.5)$ & 49.9 (5.7) & $61.7(1.5)$ \\
\hline Puerto Rican & $83.0(9.1)$ & $70.1(10)$ & $37.4(9.7)$ & $63.1(3.8)$ \\
\hline Mexican & $89.6(3.6)$ & $75.4(5.2)$ & $43.6(7.2)$ & $61.3(1.2)$ \\
\hline$P$ value & NS & $<0.001$ & $<0.001$ & $<0.001$ \\
\hline \multicolumn{5}{|l|}{ Allergy status } \\
\hline Any allergy ${ }^{c}$ & $89.6(1.6)$ & $58.8(2.3)$ & $59.2(2.3)$ & $80.0(0.8)$ \\
\hline No allergy & $87.3(2.0)$ & $58.2(3.2)$ & $55.4(3.2)$ & $68.8(0.6)$ \\
\hline$P$ value & NS & NS & NS & $<0.001$ \\
\hline \multicolumn{5}{|l|}{ Asthma action plan } \\
\hline Given asthma plan & $89.2(1.8)$ & $66.5(2.7)$ & $53.5(2.7)$ & $L^{\mathrm{d}}$ \\
\hline No asthma plan & $88.5(1.7)$ & $51.3(2.5)$ & $61.9(2.6)$ & - \\
\hline$P$ value & NS & $<0.001$ & 0.025 & \\
\hline \multicolumn{5}{|l|}{ Preventive medicine } \\
\hline Medication use & $90.5(1.5)$ & $66.5(2.2)$ & $54.7(2.4)$ & - \\
\hline No medication use & $86.1(2.1)$ & $45.5(3.0)$ & $63.1(3.0)$ & - \\
\hline$P$ value & NS & $<0.001$ & 0.031 & \\
\hline \multicolumn{5}{|l|}{ Asthma ED visit } \\
\hline ED visit & $91.6(2.2)$ & $79.2(3.3)$ & $43.7(3.9)$ & - \\
\hline No ED visit & $87.9(1.5)$ & $51.5(2.2)$ & $62.8(2.2)$ & - \\
\hline $\mathrm{p}$-value & NS & $<0.001$ & $<0.001$ & \\
\hline \multicolumn{5}{|l|}{ Reported health status } \\
\hline Fair/poor & $93.2(3.0)$ & $76.0(5.4)$ & $54.5(6.1)$ & $85.1(3.0)$ \\
\hline Good & $91.6(2.1)$ & $71.4(3.3)$ & $49.6(3.6)$ & $72.0(1.2)$ \\
\hline Very good/excellent & $87.1(1.7)$ & $50.7(2.4)$ & $61.9(2.2)$ & $71.1(0.5)$ \\
\hline$P$ value & NS & $<0.001$ & 0.014 & $<0.001$ \\
\hline \multicolumn{5}{|l|}{ Usual source of care } \\
\hline Clinic/OPD/other & $86.9(3.2)$ & $60.5(4.4)$ & $49.5(4.5)$ & $68.0(1.2)$ \\
\hline Private office/HMO & $89.3(1.4)$ & $58.6(2.1)$ & $59.1(2.2)$ & $73.6(0.6)$ \\
\hline $\mathrm{ED} /$ no place & $87.8(5.6)$ & $52.1(9.2)$ & $67.2(8.6)$ & $55.5(1.9)$ \\
\hline$P$ value & NS & NS & NS & $<0.001$ \\
\hline \multicolumn{5}{|l|}{ Health insurance } \\
\hline Any private & $87.4(1.7)$ & $53.7(2.4)$ & $59.9(2.3)$ & $74.0(0.6)$ \\
\hline Public only & $91.8(2.0)$ & $68.6(3.3)$ & $54.0(3.6)$ & $67.7(1.1)$ \\
\hline Uninsured & $90.3(3.9)$ & $63.4(7.6)$ & $55.3(7.3)$ & $61.6(1.5)$ \\
\hline$P$ value & NS & 0.002 & NS & $<0.001$ \\
\hline \multicolumn{5}{|l|}{ Smoke exposure } \\
\hline Household smoker & $91.1(2.3)$ & $70.2(3.6)$ & $59.5(3.7)$ & $75.5(1.0)$ \\
\hline Unknown & $88.2(1.5)$ & $55.1(2.1)$ & $57.4(2.2)$ & $70.3(0.6)$ \\
\hline$P$ value & NS & $<0.001$ & NS & $<0.001$ \\
\hline \multicolumn{5}{|l|}{ Family structure } \\
\hline Single parent & $89.7(2.4)$ & $64.2(3.8)$ & $52.0(4.0)$ & $70.4(1.1)$ \\
\hline Married parents & $87.9(2.0)$ & $51.0(3.1)$ & $61.8(2.9)$ & $72.3(0.7)$ \\
\hline Other 2 adult & $89.5(2.0)$ & $64.5(3.1)$ & $56.8(3.0)$ & $70.5(0.8)$ \\
\hline$P$ value & NS & 0.005 & NS & NS \\
\hline
\end{tabular}


TABle 2.

(CONTINUED)

\begin{tabular}{|c|c|c|c|c|}
\hline & \multicolumn{3}{|c|}{ Children with symptomatic asthma $(n=905)$} & \multirow{2}{*}{$\begin{array}{c}\text { Children w/out asthma }(n=13,830) \\
\geq 1 \text { total } \\
\text { absence days }\end{array}$} \\
\hline & $\begin{array}{l}\geq 1 \text { total } \\
\text { absence days }\end{array}$ & $\begin{array}{l}\geq 1 \text { asthma } \\
\text { absence days }\end{array}$ & $\begin{array}{l}\geq 1 \text { residual } \\
\text { absence days }\end{array}$ & \\
\hline \multicolumn{5}{|l|}{ Household children } \\
\hline 1 child & $89.8(1.7)$ & $60.0(2.7)$ & $58,4(2.7)$ & $73.1(0.7)$ \\
\hline 2 children & $86.0(2.1)$ & $55.8(2.8)$ & $56.4(2.9)$ & $72.3(0.7)$ \\
\hline $3+$ children & $91.4(2.2)$ & $60.9(3.8)$ & $59.2(3.8)$ & $69.6(0.9)$ \\
\hline$P$ value & NS & NS & NS & 0.007 \\
\hline \multicolumn{5}{|l|}{ Parental education } \\
\hline$<$ High school & $91.1(3.3)$ & $77.2(4.8)$ & $44.9(6.4)$ & $62.2(1.4)$ \\
\hline High school diploma $^{\mathrm{e}}$ & $92.5(1.9)$ & $65.8(3.7)$ & $61.3(3.8)$ & $71.2(1.0)$ \\
\hline College/vocational & $87.4(2.2)$ & $60.8(3.3)$ & $54.3(3.1)$ & $73.4(0.8)$ \\
\hline Bachelors degree & $90.4(2.8)$ & $48.2(4.6)$ & $64.3(4.3)$ & $71.5(1.1)$ \\
\hline Postgraduate degree & $82.9(4.4)$ & $42.7(5.4)$ & $61.0(5.3)$ & $75.5(1.3)$ \\
\hline$P$ value & NS & $<0.001$ & NS & $<0.001$ \\
\hline \multicolumn{5}{|l|}{ Family income } \\
\hline$<$ poverty & $90.9(2.7)$ & $67.9(4.5)$ & $50.7(4.8)$ & $65.2(1.4)$ \\
\hline $100-199 \%$ poverty & $90.1(2.9)$ & $70.3(4.7)$ & $51.7(4.3)$ & $69.2(1.1)$ \\
\hline $200-499 \%$ poverty & $89.0(2.3)$ & $55.2(3.3)$ & $61.0(3.1)$ & $72.7(0.7)$ \\
\hline $500 \%+$ poverty & $85.2(3.4)$ & $45.8(4.7)$ & $63.8(4.6)$ & $75.8(1.1)$ \\
\hline$P$ value & NS & $<0.001$ & NS & $<0.001$ \\
\hline \multicolumn{5}{|l|}{ Urbanicity } \\
\hline Central city & $85.6(2.5)$ & $64.4(3.4)$ & $46.5(3.6)$ & $67.1(1.0)$ \\
\hline Other MSA & $89.4(1.7)$ & $56.3(2.6)$ & $63.1(2.6)$ & $72.1(0.7)$ \\
\hline Outside MSA & $91.8(2.5)$ & $43.7(2.6)$ & $58.2(3.9)$ & $75.0(1.0)$ \\
\hline$P$ value & NS & NS & 0.002 & $<0.001$ \\
\hline \multicolumn{5}{|l|}{ Region } \\
\hline Northeast & $87.8(2.8)$ & $59.3(4.2)$ & $57.8(4.2)$ & $74.7(1.1)$ \\
\hline Midwest & $89.9(2.3)$ & $55.3(4.0)$ & $62.0(3.7)$ & $76.3(1.0)$ \\
\hline South & $87.3(2.4)$ & $62.8(2.9)$ & $53.4(3.2)$ & $68.9(0.8)$ \\
\hline West & $91.2(2.3)$ & $54.9(3.9)$ & $60.6(4.0)$ & $67.5(1.0)$ \\
\hline$P$ value & NS & NS & NS & $<0.001$ \\
\hline \multicolumn{5}{|l|}{ Interview quarter } \\
\hline 1st quarter & $86.2(2.9)$ & $57.0(3.7)$ & $55.0(3.8)$ & $73.7(0.9)$ \\
\hline 2nd quarter & $90.3(2.3)$ & $58.3(3.9)$ & $60.1(4.1)$ & $73.3(1.0)$ \\
\hline 3rd quarter & $94.2(1.5)$ & $62.7(3.9)$ & $62.9(3.9)$ & $69.1(1.0)$ \\
\hline 4th quarter & $85.5(2.7)$ & $56.5(3.7)$ & $54.5(3.7)$ & $69.4(1.0)$ \\
\hline p-value & 0.016 & NS & NS & $<0.001$ \\
\hline
\end{tabular}

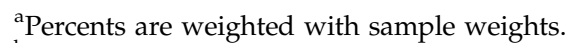

${ }^{\mathrm{b}} P$ value result of chi-square test for differences in absence day variables for children with and without symptomatic asthma by levels of descriptive variables.

${ }^{\mathrm{c} C h i l d r e n}$ reported to have hay fever, other respiratory allergy, eczema, and/or food allergy.

${ }^{\mathrm{d}}$ The National Health Interview Survey did not assess children without asthma for asthma interventions or outcomes.

'Includes GED and equivalent diplomas.

NS, not significant.

values for missing income according to recommended methods. ${ }^{15}$ Residence was categorized by urbanicitycentral city within a metropolitan statistical area (MSA), MSA outside a central city, and nonurban (outside an MSA) —and U.S. Census region: Northeast, South, Midwest, and West.

We included the interview quarter given the seasonality of asthma school absences, which peak in the fall. ${ }^{16}$ Although NHIS sampling strategy is designed to avoid seasonal biaseach weekly sample is nationally representative ${ }^{17}$ - parents surveyed during quarters more removed from asthma school absences may be less likely to recall absences.

\section{Analyses}

First, we describe the study populations by assessing differences in characteristics between the 2 samples of children with symptomatic asthma and with no asthma diagnosis; chi-square tests at the 0.05 level were used to determine statistically significant differences. SUDAAN software (Release 10.0; Research Triangle Institute) was used for this and all analyses due to the complex design of the NHIS.

Next, among the children with symptomatic asthma, we compared the proportions of children with at least 1 total absence day, with at least 1 asthma absence day, and with at least 1 residual day by levels of child characteristics. Overall chisquare tests were used to determine if these absence proportions differed by levels of child characteristic, and for those characteristics with a $P$ value $<0.05$ and multiple categories, pairwise comparisons between categories were made with 2sided $t$-test with the critical value of 1.96 at the 0.05 level of significance. For comparison, the proportions of total absence days among children without asthma were similarly examined. 


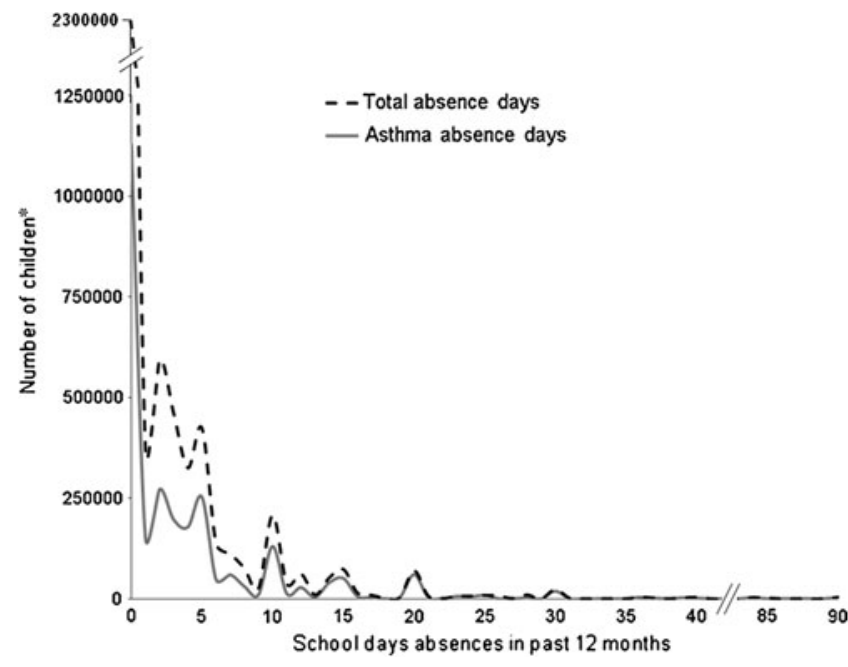

FIG. 2. Distribution of total absence days and asthma absence days among children with symptomatic asthma $(n=905)$. ${ }^{*}$ Weighted to national numbers.

We then used logistic regression to (1) evaluate the association between covariates and asthma absence days among children with symptomatic asthma, (2) evaluate the association between covariates and residual absence days among children with symptomatic asthma, and (3) evaluate the association between covariates and total absence days among children without asthma. For each of these 3 evaluations, the final logistic model was constructed by removing variables with $P$ value $>0.15$ that also did not result in a $\geq 10 \%$ change in other covariate coefficients. We assessed collinearity by examining the difference in standard errors between bivariate and multivariate models and the change in standard errors when variables were removed and reintroduced.

Because the distribution of absence days was skewed, we compared unadjusted counts of absence days between groups using medians. In the stratified regression models, absence days were dichotomized as any versus none. Due to the high prevalence of having any absence days $(>50 \%)$, odds ratios overestimate relative risk. Therefore, we used SUDAAN to calculate the adjusted risk ratio (ARR) with the predicted marginal (PREDMARG) statement which estimates predicted marginals, and the adjusted risk ratio (ADJRR) option to convert predicted marginals to ARRs. ${ }^{18}$

To assess associations between covariates and the number of asthma and residual absence days, we used a linear regression model with the log-transformed number of absence days among the sample of children with symptomatic asthma with $\geq 1$ asthma absence day $(n=552)$.

\section{Results}

Among the 17,614 children aged 5-17 years in the 20022003 NHIS, 1,115 had symptomatic asthma in the past 12 months; of these, 905 (81\%) had complete data (Fig. 1). Compared with the included sample of children with symptomatic asthma, excluded children with symptomatic asthma were more socioeconomically disadvantaged and had greater asthma healthcare resource use. Children without an asthma diagnosis were analyzed separately $(N=$
13,830). Similar exclusion criteria were applied for this sample $(3,784$, or $27 \%$ of 17,614 were excluded for missing covariates). Table 1 shows that compared with children without an asthma diagnosis, a higher percentage of children with symptomatic asthma were younger, were male, had allergies, were in poorer health, and lived in a single-parent household; health insurance status, usual source of health care, parental education, and race/ethnicity also differed between the 2 study populations. Given that many of these differences relate to risk factors of having asthma, these populations were analyzed separately.

Almost $60 \%$ of children with symptomatic asthma in the past 12 months missed $\geq 1$ day of school in the previous year for asthma, and $89 \%$ had $\geq 1$ absence for any illness/injury (total absence days) versus $71 \%$ of children without asthma (Table 2). For all following results, only comparisons that are statistically significant are mentioned (2-sided $t$-test significance level 0.05 or less). Among children with symptomatic asthma, the groups with higher proportions with $\geq 1$ asthma absence day were non-Hispanic black and Mexican race/ethnicity compared with non-Hispanic white, had an asthma action plan, used preventive asthma medication, had an asthma ED visit in the past 12 months, had fair/poor or good health status compared with very good/excellent health status, had public versus private insurance, were exposed to a household smoker, lived in a single-parent or other 2-adult family versus with married parents, had parents with any category of education lower than a bachelors degree compared with bachelors degree, and had family income less than poverty or $100 \%-199 \%$ poverty level compared with $500 \%$ or greater of the poverty level. Characteristics associated with greater proportions of $\geq 1$ other illness / injury absences among children with asthma (residual absence days) differed: 10-13 years and 14-17 years compared with 5-9 years, female sex, non-Hispanic white race/ ethnicity compared with each of the other race/ethnic categories, not having an asthma action plan or an asthma ED visit in the past 12 months, very good/excellent health status compared with good health status, and living outside an MSA compared with within a central city.

Most children missed no or little school $-60 \%$ missed $\leq 5$ days (Fig. 2). Peaks along the distribution at multiples of 5 suggest that many parents estimated absence days. The median number of total absence days was 1.6 (standard error 0.03) among children without asthma versus 4.3 (standard error 0.14) among children with symptomatic asthma.

Multivariate analyses were conducted separately for children with symptomatic asthma and those without an asthma diagnosis. For asthma absence days among children with symptomatic asthma (Table 3, model 1), ARRs were significantly elevated (the $95 \%$ confidence interval excluded the value of 1.0) for males, non-Hispanic black and children of Mexican ethnicity, having an asthma action plan, preventive medication use, an asthma $E D$ visit in the past 12 months, those with good (versus very good/excellent) health, exposure to a household smoker, and parental education less than high school. Residual absence day results among children with symptomatic asthma (model 2) showed nearly the opposite pattern.

Among children without asthma, ARRs for total absence days (model 3) were elevated for fair/poor or good (versus very good/excellent) health status, exposure to a household smoker, and higher parental education. Race/ethnicity other 
Table 3. Adjusted Risk Ratios ${ }^{\mathrm{a}}$ for $\geq 1$ Absence Days by Type of Absence

\begin{tabular}{|c|c|c|c|}
\hline & \multicolumn{2}{|c|}{ Children with symptomatic asthma $(n=905)$} & \multirow{2}{*}{$\begin{array}{c}\text { Children without asthma }(n=13,830) \\
\text { Model 3: } \\
\text { ARR }(95 \% \text { CI }) \text { of } \geq 1 \\
\text { total absence day }\end{array}$} \\
\hline & $\begin{array}{c}\text { Model 1: } \\
\text { ARR (95\% CI) of } \geq 1 \\
\text { asthma absence day }\end{array}$ & $\begin{array}{l}\text { Model 2: } \\
\text { ARR (95\% CI) of } \geq 1 \\
\text { residual absence day }\end{array}$ & \\
\hline \multicolumn{4}{|l|}{ Gender } \\
\hline Male & $1.13(1.00,1.27)$ & $0.87(0.77,0.98)$ & $0.98(0.95,1.00)$ \\
\hline Female & ref & ref & ref \\
\hline \multicolumn{4}{|l|}{ Race/ethnicity } \\
\hline NH white & ref & ref & ref \\
\hline NH black & $1.20(1.03,1.40)$ & $0.54(0.42,0.69)$ & $0.77(0.73,0.81)$ \\
\hline AIAN/other & $1.08(0.87,1.34)$ & $0.76(0.61,0.96)$ & $0.82(0.78,0.86)$ \\
\hline Puerto Rican & $1.16(0.82,1.65)$ & $0.61(0.38,0.98)$ & $0.82(0.73,0.93)$ \\
\hline Mexican & $1.29(1.09,1.53)$ & $0.65(0.45,0.95)$ & $0.84(0.80,0.88)$ \\
\hline \multicolumn{4}{|l|}{ Asthma action plan } \\
\hline Given asthma plan & $1.17(1.04,1.33)$ & $0.94(0.83,1.07)$ & - \\
\hline No asthma plan & ref & ref & \\
\hline \multicolumn{4}{|l|}{ Preventive medicine } \\
\hline Medication use & $1.21(1.05,1.39)$ & $0.92(0.80,1.06)$ & - \\
\hline No medication use & ref & ref & \\
\hline \multicolumn{4}{|l|}{ Asthma ED visit } \\
\hline ED visit in past $12 \mathrm{mo}$ & $1.42(1.25,1.61)$ & $0.78(0.66,0.94)$ & - \\
\hline No ED visit & ref & ref & \\
\hline \multicolumn{4}{|l|}{ Reported health status } \\
\hline Fair/poor & $1.19(0.95,1.49)$ & $1.05(0.86,1.30)$ & $1.24(1.16,1.31)$ \\
\hline Good & $1.23(1.07,1.40)$ & $0.93(0.80,1.08)$ & $1.07(1.03,1.10)$ \\
\hline Very good/excellent & ref & ref & ref \\
\hline \multicolumn{4}{|l|}{ Usual source of care } \\
\hline Clinic/OPD/other & $0.93(0.78,1.10)$ & $0.88(0.72,1.06)$ & $0.97(0.94,1.01)$ \\
\hline Private office/HMO & ref & ref & ref \\
\hline $\mathrm{ED} /$ no place & $0.67(0.43,1.06)$ & $1.28(1.06,1.54)$ & $0.85(0.80,0.91)$ \\
\hline \multicolumn{4}{|l|}{ Health insurance } \\
\hline Private & ref & ref & ref \\
\hline Public & $0.95(0.80,1.11)$ & $1.13(0.97,1.32)$ & $0.98(0.95,1.02)$ \\
\hline Uninsured & $1.01(0.78,1.29)$ & $1.03(0.81,1.32)$ & $0.94(0.90,0.99)$ \\
\hline \multicolumn{4}{|l|}{ Smoke exposure status } \\
\hline Household smoker & $1.25(1.10,1.42)$ & $0.98(0.84,1.15)$ & $1.06(1.03,1.09)$ \\
\hline Unknown & ref & ref & ref \\
\hline \multicolumn{4}{|l|}{ Parental education } \\
\hline$<$ High school & $1.39(1.10,1.76)$ & $0.73(0.53,1.01)$ & $0.99(0.94,1.05)$ \\
\hline High school degree & $1.20(0.98,1.47)$ & $1.00(0.84,1.20)$ & $1.03(0.99,1.07)$ \\
\hline College/vocational & $1.17(0.97,1.42)$ & $0.89(0.75,1.06)$ & $1.05(1.02,1.10)$ \\
\hline Bachelors degree & ref & ref & ref \\
\hline Postgraduate degree & $0.90(0.69,1.19)$ & $0.92(0.75,1.14)$ & $1.05(1.00,1.11)$ \\
\hline \multicolumn{4}{|l|}{ Interview quarter } \\
\hline 1st quarter & $1.06(0.90,1.26)$ & $0.98(0.82,1.17)$ & $1.06(1.02,1.10)$ \\
\hline 2nd quarter & $1.15(0.98,1.37)$ & $1.01(0.85,1.21)$ & $1.05(1.02,1.09)$ \\
\hline 3rd quarter & $1.14(0.97,1.35)$ & $1.12(0.95,1.32)$ & $1.00(0.96,1.03)$ \\
\hline 4th quarter & ref & ref & ref \\
\hline
\end{tabular}

adjusted for all covariates shown in table.

${ }^{\mathrm{b}}$ Residual absence days are the total absence school days due any illness/injury minus asthma absence days.

ARR, adjusted risk ratio; ref, reference group.

than non-Hispanic white, not having a source of health care, and being uninsured reduced the risk of total illness absences among children without asthma.

To assess risk factors associated with greater number of asthma absences among the subset of children with symptomatic asthma who had at least 1 asthma absence day, we used a linear regression model for the log-transformed number of days. Having an asthma management plan or an asthma ED visit were associated with an increased number of asthma absences (Table 4). Having fair/poor or good health status, public health insurance, and asthma healthcare resource use were also associated with a greater number of asthma absence days, but exposure to a household smoker was not.

The lack of association between exposure to a household smoker and the number of asthma absences days raised the question of whether smoke exposure had a greater association with absences among children with less severe asthma. Using the covariates in Table 4, we assessed the risk of having any versus no asthma absence days with the sample of children with symptomatic asthma stratified by asthma 
Table 4. Linear Regression ${ }^{\mathrm{a}}$ : Number of Asthma Absence Days Among Children with Symptomatic Asthma with $\geq 1$ Asthma Absence Day $(N=552)$

\begin{tabular}{|c|c|}
\hline & Beta coefficient $(95 \% \mathrm{CI})$ \\
\hline \multicolumn{2}{|l|}{ Gender } \\
\hline Male & $-0.03(-0.18,0.12)$ \\
\hline Female & ref \\
\hline \multicolumn{2}{|l|}{ Race/ethnicity } \\
\hline NH white & ref \\
\hline NH black & $0.01(-0.18,0.21)$ \\
\hline AIAN/other & $-0.13(-0.32,0.07)$ \\
\hline Puerto Rican & $0.09(-0.29,0.46)$ \\
\hline Mexican & $0.07(-0.24,0.38)$ \\
\hline \multicolumn{2}{|l|}{ Asthma action plan } \\
\hline Given asthma plan & $0.22(0.06,0.39)$ \\
\hline No asthma plan & ref \\
\hline \multicolumn{2}{|l|}{ Preventive medicine } \\
\hline Medication use & $-0.03(-0.20,0.15)$ \\
\hline No medication use & ref \\
\hline \multicolumn{2}{|l|}{ Asthma ED visit } \\
\hline ED visit in past $12 \mathrm{mo}$ & $0.48(0.31,0.64)$ \\
\hline No ED visit & ref \\
\hline \multicolumn{2}{|l|}{ Reported health status } \\
\hline Fair/poor & $0.60(0.32,0.88)$ \\
\hline Good & $0.18(0.01,0.35)$ \\
\hline Very good/excellent & ref \\
\hline \multicolumn{2}{|l|}{ Usual source of care } \\
\hline Clinic/OPD/other & $-0.01(-0.20,0.19)$ \\
\hline Private office/HMO & ref \\
\hline $\mathrm{ED} /$ no place & $-0.11(-0.54,0.32)$ \\
\hline \multicolumn{2}{|l|}{ Health insurance } \\
\hline Private & ref \\
\hline Public & $0.19(0.00,0.37)$ \\
\hline Uninsured & $0.10(-0.23,0.43)$ \\
\hline \multicolumn{2}{|l|}{ Smoke exposure status } \\
\hline Household smoker & $0.05(-0.14,0.24)$ \\
\hline Unknown & ref \\
\hline \multicolumn{2}{|l|}{ Parental education } \\
\hline$<$ High school & $0.12(-0.17,0.41)$ \\
\hline High school degree & $-0.18(-0.43,0.08)$ \\
\hline College/vocational & $-0.02(-0.25,0.21)$ \\
\hline Bachelors degree & ref \\
\hline Postgraduate degree & $0.22(-0.10,0.54)$ \\
\hline \multicolumn{2}{|l|}{ Interview quarter } \\
\hline 1st quarter & $-0.08(-0.29,0.12)$ \\
\hline 2nd quarter & $-0.03(-0.25,0.19)$ \\
\hline 3rd quarter & $-0.22(-0.43,0.00)$ \\
\hline 4th quarter & ref \\
\hline
\end{tabular}

${ }^{\mathrm{a} S e m i l o g}$ linear regression, adjusted for all covariates shown in table.

CI, confidence interval.

healthcare resource use (Table 5). Although healthcare resource use cannot be equated with severity, it is likely that those with an asthma ED visit and/or preventive medication may face greater asthma morbidity. Among children without an asthma ED visit or preventive medication, ARRs of having $\geq 1$ asthma absence day were elevated for males, all race/ ethnicity groups except non-Hispanic white, exposure to a household smoker, and lower parental education.

Because the NHIS incompletely captures exposure to household smoking, we examined the 2005 NHIS in which a supplemental questionnaire on household smoking provided more detailed data than are available in the 2002-2003 NHIS. In the 2005 NHIS, $18 \%$ of children lived with a sample adult
Table 5. Factors Associated with $\geq 1$ Asthma School Absence Days Among Children with Symptomatic Asthma, by Healthcare Resource Use, Adjusted Risk Ratio (95\% Confidence Interval)

\begin{tabular}{|c|c|c|}
\hline & $\begin{array}{l}\text { Children with } \\
\text { asthma ED } \\
\text { visit and/or } \\
\text { preventive } \\
\text { med use }\end{array}$ & $\begin{array}{l}\text { Children with } \\
\text { no asthma } \\
\text { ED visit or } \\
\text { preventive } \\
\text { med use }\end{array}$ \\
\hline$N$ & 627 & 278 \\
\hline \multicolumn{3}{|l|}{ Gender } \\
\hline Male & $1.03(0.91,1.17)$ & $1.52(1.08,2.15)$ \\
\hline Female & ref & ref \\
\hline \multicolumn{3}{|l|}{ Race/ethnicity } \\
\hline NH white & ref & ref \\
\hline NH black & $1.15(0.99,1.34)$ & $1.54(1.04,2.29)$ \\
\hline AIAN/other & $0.95(0.75,1.20)$ & $1.63(1.03,2.60)$ \\
\hline Puerto Rican & $0.99(0.68,1.44)$ & $1.99(1.00,3.84)$ \\
\hline Mexican & $1.23(1.05,1.44)$ & $1.70(1.06,2.75)$ \\
\hline \multicolumn{3}{|l|}{ Asthma action plan } \\
\hline Given asthma plan & $1.12(0.98,1.27)$ & $1.23(0.89,1.69)$ \\
\hline No asthma plan & ref & ref \\
\hline \multicolumn{3}{|l|}{ Reported health status } \\
\hline Fair/poor & $1.24(1.03,1.50)$ & $1.03(0.45,2.35)$ \\
\hline Good & $1.24(1.08,1.43)$ & $1.24(0.87,1.75)$ \\
\hline Very good/excellent & ref & ref \\
\hline \multicolumn{3}{|l|}{ Usual source of care } \\
\hline Clinic/OPD/other & $1.02(0.87,1.20)$ & $0.78(0.50,1.24)$ \\
\hline Private office/HMO & ref & ref \\
\hline $\mathrm{ED} /$ no place & $0.58(0.32,1.05)$ & $0.86(0.45,1.66)$ \\
\hline \multicolumn{3}{|l|}{ Health insurance } \\
\hline Private & ref & ref \\
\hline Public & $96(0.81,1.13)$ & $1.03(0.68,1.58)$ \\
\hline Uninsured & $1.09(0.85,1.40)$ & $0.79(0.37,1.65)$ \\
\hline \multicolumn{3}{|l|}{ Smoke exposure status } \\
\hline Household smoker & $1.15(1.00,1.32)$ & $1.53(1.09,2.13)$ \\
\hline Unknown & f & ref \\
\hline \multicolumn{3}{|l|}{ Parental education } \\
\hline$<$ High school & $1.26(0.98,1.60)$ & $1.94(1.09,3.44)$ \\
\hline High school degree & $1.17(0.94,1.45)$ & $1.32(0.79,2.22)$ \\
\hline College/vocational & $1.16(0.95,1.43)$ & $1.15(0.70,1.89)$ \\
\hline Bachelors degree & ref & ref \\
\hline Postgraduate degree & $0.91(0.68,1.23)$ & $0.83(0.44,1.56)$ \\
\hline \multicolumn{3}{|l|}{ Interview quarter } \\
\hline 1st quarter & $1.10(0.91,1.33)$ & $1.10(0.74,1.64)$ \\
\hline 2nd quarter & $1.13(0.94,1.35)$ & $1.15(0.77,1.71)$ \\
\hline 3rd quarter & $1.20(1.00,1.43)$ & $0.98(0.62,1.55)$ \\
\hline 4th quarter & ref & ref \\
\hline
\end{tabular}

who reported smoking, 16\% were not linked with a sample adult interview, 63\% lived in a nonsmoking household, and $3 \%$ lived in a household in which some other adult smoked. Consequently, based on these 2005 data, for children in the 2002-2003 sample, with sample adult information, misclassification of children having unknown exposure to smoke is likely to be small $(\sim 3 \%)$.

\section{Discussion}

The objective of this analysis of children with symptomatic asthma from a national health survey was to identify risk factors for asthma-related school absences. We found that among this group, asthma absences were associated with male gender, non-Hispanic black and Mexican race/ethnicity, poorer health status, lower parental education, indicators of 
greater asthma healthcare resource use, and exposure to a household smoker. Many of these characteristics (male gender, non-Hispanic black ethnicity, low parental education, and exposure to tobacco smoke) are also risk factors for having asthma. ${ }^{7,19-22}$ To the extent that these characteristics may also be markers for more severe or poorly controlled asthma, ${ }^{11,13,21,23}$ the overlap of risk factors for having asthma and asthma-related absences from school is plausible. Previous studies have found that children with poorly controlled nighttime symptoms versus no nighttime symptoms, ${ }^{8}$ or more severe asthma compared with less severe asthma, 2,8,24 have increased risk of school absence. These studies all recommend evaluating asthma control as an avenue to decrease asthma morbidity and school absences.

One specific means to improving control is suggested by this and other studies ${ }^{25,26}$ and is supported by the Guidelines for the Diagnosis and Management of Asthma ${ }^{7}$ : controlling exposure to second-hand tobacco smoke. When the sample of children with symptomatic asthma was stratified by asthma healthcare resource use, we observed a larger association between asthma-related school absences and exposure to a household smoker among children with low healthcare resource use. This pattern suggests that exposure tobacco smoke could be an important consideration in children with asthma who may not have other apparent risk factors for adverse asthma outcomes. Although exposure to second-hand tobacco smoke was incompletely assessed in our study, our findings support the recommendation that all children with asthma be screened for exposure to tobacco smoke. ${ }^{7}$

Although children of Mexican ethnicity have among the lowest rates of asthma prevalence, ${ }^{22}$ we found that Mexican ethnicity was associated with higher asthma absences. Freeman et al. $^{25}$ found that Mexican children had low asthma prevalence compared with Puerto Rican and nonHispanic black children, and had lower exposure to secondhand tobacco smoke and pets than other racial/ethnic groups. They noted, however, that Mexican children were also less likely to have health insurance than other groups; lack of insurance and health care access has been found to be a risk factor for poorly controlled asthma. ${ }^{23}$ Another study ${ }^{13}$ noted that Puerto Rican and Mexican children with asthma had worse parent-reported physical health and that Puerto Rican children had worse emotional health compared with other Hispanic subgroups. The Puerto Rican sample, a group with high asthma prevalence, ${ }^{22}$ was likely too small in our study to detect significant differences in risk for school absences.

Much of the literature focuses on whether children with asthma miss more school, and findings have been mixed. Some suggest that children with asthma have a greater school absence rate, ${ }^{3,5,6}$ whereas others find only children with more severe asthma miss more school, ${ }^{2}$ and yet others find children with asthma have the same rate of absences as their peers. ${ }^{4}$ Although not a primary goal of the analysis, we found that a greater proportion of children with asthma miss school and that they miss a greater median number of school days. However, our sample excluded children with wellcontrolled or asymptomatic asthma because the NHIS did not asses asthma-specific absences for this group. The difference between children with symptomatic asthma and those without asthma is most likely higher than if children with well-controlled asthma could be included in the group with asthma.
Another objective of our study was to determine if risk factors for asthma-related absences were different than for other types of absences. Stratified models were used in multivariate analyses and thus did not directly compare risk factors for absences between children with symptomatic asthma and children without asthma. Nonetheless, risk factors associated with other illness/injury absences (residual absences) among children with symptomatic asthma differed from those observed for illness/injury absences among children without asthma. Further, among children with symptomatic asthma, we observed nearly the opposite pattern for absences due to other illness/injury (residual absences) compared with asthma absences. Possible explanations include the following: (1) risk factors for asthma absenteeism are different than for other illnesses, (2) other common reasons for absenteeism (eg, upper respiratory infections and allergic symptoms) may overlap with or act as a trigger for asthma symptoms and are captured by asthma absences rather than residual absence days, and/or (3) asthma absences may raise the threshold for other types of absences (ie, asthma crowds out other reasons for absences). The latter 2 explanations raise speculation that decreasing asthma absenteeism may not necessarily decrease overall absenteeism among children with asthma.

There are several limitations to our study. Disease severity is not fully assessed and likely remains incompletely controlled, and the associations with asthma absences may be proxy measures for more severe or poorly controlled disease. Excluding children with missing data may bias findings due to their more disadvantaged backgrounds and higher asthma healthcare resource use. We excluded children with symptomatic asthma with the implausible pattern of higher reported asthma absences than total absences. A sensitivity analysis including the 58 children excluded for this reason (total $n=963$ ) yielded nearly identical results as the analysis of the final sample $(n=905$, Table 3 , model 1 , which analyzed adjusted associations between covariates and asthma absence days). Nevertheless, it remains possible that among the included sample of children with symptomatic asthma, the reason for reported absences (asthma versus residual absences) may be misclassified. The recall period for school absence days was lengthy. There could be seasonal bias in recall (parents may be more likely to recall absences close in time to the interview), a bias we attempted to address by adjusting for interview quarter. Household smoke exposure was determined by proxy report. However, in a study where both the adult smoking status and serum cotinine of children were ascertained, cotinine levels were an order of magnitude higher among children with reported household smoker exposure. ${ }^{27}$ NHIS smoking data were also incomplete as discussed above. Parental decisions to keep a child home from school may also be related to flexibility in work hours, availability of other caretakers, and differing perspectives of illness severity ${ }^{28}$ Because the NHIS also does not collect data on school performance, impact on academic achievement cannot be assessed. Finally, the data are crosssectional so causation cannot be inferred.

National data for children with symptomatic asthma identified an association between asthma-related school absences and male gender, non-Hispanic black and Mexican race/ ethnicity, greater asthma healthcare resource use, poorer health status, lower parental education, and exposure to a household smoker. This analysis supports prior research and national 
asthma management guidelines that specify that school absences due to asthma may help identify children in greater need of asthma evaluation and management.

\section{Author Disclosure Statement}

This analysis was undertaken at the Centers for Disease Control and Prevention. The findings and conclusions in this report are those of the authors and do not necessarily represent the view of the Centers for Disease Control and Prevention. None of the 3 authors have any disclosures of financial support of conflicts of interest to declare.

\section{References}

1. Akinbami LJ. Asthma prevalence, health care use and mortality: United States, 2003-2005. Atlanta, GA: Centers for Disease Control and Prevention, 2007. Available at www.cdc.gov/nchs/ products/pubs/pubd/hestats/ashtma03-05/asthma03-05.htm, accessed April 1, 2007.

2. Moonie SA, Sterling DA, Figgs L, Castro M. Asthma status and severity affects missed school days. J Sch Health 2006; 76:18-24.

3. Silverstein MD, Mair JE, Katusic SK, Wollan PC, O'connell EJ, Yunginger JW. School attendance and school performance: a population-based study of children with asthma. J Pediatr 2001; 139:278-283.

4. Millard MW, Johnson PT, Hilton A, Hart M. Children with asthma miss more school: fact or fiction? Chest 2009; 135:303-306.

5. Moonie S, Sterling DA, Figgs LW, Castro M. The relationship between school absence, academic performance, and asthma status. J Sch Health 2008; 78:140-148.

6. Fowler MG, Davenport MG, Garg R. School functioning of US children with asthma. Pediatrics 1992; 90:939-944.

7. National Asthma Education and Prevention Program. Expert Panel Report 3: Guidelines for the Diagnosis and Management of Asthma. Bethesda, MD: National Heart, Lung and Blood Institute, National Institutes of Health: U.S. Department of Health and Human Services, 2007. Report No.: NIH Publication No. 07-4051.

8. Diette GB, Markson L, Skinner EA, Nguyen TT, Gatt-Bergstrom $\mathrm{P}, \mathrm{Wu} \mathrm{AW}$. Nocturnal asthma in children affects school attendance, school performance, and parents' work attendance. Arch Pediatr Adolesc Med 2000; 154:923-928.

9. National Center for Health Statistics. National Health Interview Survey: questionnaires, datasets, and related documentation 1997 to the present. Atlanta, GA: Centers for Disease Control and Prevention, 2010. Available at www.cdc.gov/nchs/nhis/quest_ data_related_1997_forward.htm, accessed December 1, 2009.

10. Boudreaux ED, Emond SD, Clark S, Camargo CA Jr. Race/ ethnicity and asthma among children presenting to the emergency department: differences in disease severity and management. Pediatrics 2003; 111(5 Pt 1):e615-e621.

11. Finkelstein JA, Lozano P, Farber HJ, Miroshnik I, Lieu TA. Underuse of controller medications among medicaid-insured children with asthma. Arch Pediatr Adolesc Med 2002; 156:562-567.

12. Halterman JS, Aligne CA, Auinger P, McBride JT, Szilagyi PG. Inadequate therapy for asthma among children in the United States. Pediatrics 2000; 105(1 Pt 3):272-276.

13. Lieu TA, Lozano P, Finkelstein JA, et al. Racial/ethnic variation in asthma status and management practices among children in managed medicaid. Pediatrics 2002; 109:857-865.

14. U.S. Census Bureau. How the Census Bureau Measures Poverty (Official Measure). Suitland, MD: U.S. Census Bureau, Housing and Household Economic Statistics Division, 2007. Available at www.census.gov/hhes/www/poverty/povdef.html, accessed December 1, 2009.

15. Schenker N, Raghunathan TE, Chiu PL, Makuc DM, Zhang G, Cohen AJ. Multiple imputation of family income and personal earnings in the National Health Interview Survey: methods and examples. Hyattsville, MD: National Center for Health Statistics, 2008. Available at www.cdc.gov/nchs/data/nhis/tecdoc.pdf, accessed December 1, 2009.

16. Sears MR. Epidemiology of asthma exacerbations. J Allergy Clin Immunol 2008; 122:662-668.

17. Botman SL, Moore TF, Moriarity CL, Parsons VL. Design and estimation for the National Health Interview Survey, 1995-2004. Hyattsville, MD: National Center for Health Statistics, 2000. Report No.: 130.

18. Research Triangle Institute. SUDAAN language manual, release 10. Research Triangle Park, NC: Research Triangle Institute, 2008.

19. Sears MR. Epidemiology of childhood asthma. Lancet 1997; 350:1015-1020.

20. Subbarao P, Mandhane PJ, Sears MR. Asthma: epidemiology, etiology and risk factors. CMAJ 2009; 181:E181-E190.

21. Meurer JR, George V, Subichin S, Yauck J, Layde P. Asthma severity among children hospitalized in 1990 and 1995. Arch Pediatr Adolesc Med 2000; 154:143-149.

22. Lara M, Akinbami L, Flores G, Morgenstern H. Heterogeneity of childhood asthma among Hispanic children: Puerto Rican children bear a disproportionate burden. Pediatrics 2006; 117:43-53.

23. Halterman JS, Auinger P, Conn KM, Lynch K, Yoos HL, Szilagyi PG. Inadequate therapy and poor symptom control among children with asthma: findings from a multistate sample. Ambul Pediatr 2007; 7:153-159.

24. Liu AH, Gilsenan AW, Stanford RH, Lincourt W, Ziemiecki R, Ortega H. Status of asthma control in pediatric primary care: results from the pediatric Asthma Control Characteristics and Prevalence Survey Study (ACCESS). J Pediatr 2010; 157:276-281.

25. Freeman NC, Schneider D, McGarvey P. Household exposure factors, asthma, and school absenteeism in a predominantly Hispanic community. J Expo Anal Environ Epidemiol 2003; 13:169-176.

26. Halterman JS, Szilagyi PG, Yoos HL, et al. Benefits of a schoolbased asthma treatment program in the absence of secondhand smoke exposure: results of a randomized clinical trial. Arch Pediatr Adolesc Med 2004; 158:460-467.

27. Marano C, Schober SE, Brody DJ, Zhang C. Secondhand tobacco smoke exposure among children and adolescents: United States, 2003-2006. Pediatrics 2009; 124:1299-1305.

28. Lipstein EA, Perrin JM, Kuhlthau KA. School absenteeism, health status, and health care utilization among children with asthma: associations with parental chronic disease. Pediatrics 2009; 123:e60-e66.

Address correspondence to: Lara Akinbami, M.D.

National Center for Health Statistics Centers for Disease Control and Prevention 3311 Toledo Road Hyattsville, MD 20782

E-mail: LAkinbami@cdc.gov

Received for publication April 23, 2010; accepted after revision September 9, 2010. 